\title{
USOS DE TECNOLOGIAS DIGITAIS EM PRÁTICAS DE LETRAMENTOS COM LÍNGUA INGLESA POR ESTUDANTES DO ENSINO MÉDIO
}

\author{
Cleide Beatriz Tambosi Pisetta* \\ Isabela Vieira Barbosa ${ }^{* *}$ \\ Adriana Fischer
}

RESUMO: As tecnologias digitais estão diariamente na vida das pessoas e vêm colaborando com a aprendizagem de outras línguas. O objetivo deste trabalho é depreender usos de tecnologias digitais em práticas de letramentos com língua inglesa por estudantes do ensino médio. Através de capturas de tela de redes sociais e bate-papo dos jogos, bem como entrevistas semiestruturada em grupo. Foi possível analisar interações dos estudantes do ensino médio com colegas de outros países, posicionamentos acerca do uso do inglês dentro e fora da escola, bem como indícios das condições escolares do ensino de língua inglesa. As análises dos dados baseiam-se em enfoques dos Estudos dos Letramentos e das tecnologias digitais, os quais reconhecem o valor das novas tecnologias não apenas em sala de aula, mas também em práticas vernaculares. Para os sujeitos da pesquisa, a aprendizagem que ocorre dentro do ambiente virtual, especificamente nos jogos online, se caracteriza como como autônoma e interativa, enquanto as práticas em sala de aula são percebidas como as que oportunizam a aprendizagem da escrita padrão do inglês. Entretanto, apesar de os estudantes apontarem a escola e a internet como distantes, os sujeitos não negam as contribuições da escola na aprendizagem da língua inglesa, porém não estabelecem uma ligação entre as práticas vernaculares dos jogos online e das práticas dominantes escolares.

PALAVRAS-CHAVE: Internet; Jogos online; Língua inglesa.

\section{Introdução}

O uso das tecnologias digitais tem colaborado e facilitado a comunicação entre pessoas em todo o mundo. Na aprendizagem de uma língua estrangeira, o tema deste estudo,

\footnotetext{
* Mestre em Educação na linha de Linguagens, Arte e Educação pela Universidade Regional de Blumenau (Furb). Faz parte do Grupo de Pesquisa Linguagens e Letramentos na Educação. Faz parte da equipe editorial Atos de Pesquisa - Revista do Programa de Pós-Graduação em Educação da Universidade Regional de Blumenau (PPGE/Furb) e Bolsista Furb (2016-2018).

** Doutoranda em Educação pela Universidade Regional de Blumenau (Furb). Mestre em Educação pela Furb.

*** Doutora e mestre em Linguística pela Universidade Federal de Santa Catarina (Ufsc). Docente do Centro de Ciências da Educação, Artes e Letras (Departamento de Letras) e do Programa de Pós-Graduação em Educação (Mestrado e Doutorado) da Universidade Regional de Blumenau (Furb). Atuou como docente no Programa de Pós-Graduação em Letras (PPGL, Mestrado e Doutorado) da Universidade Católica de Pelotas (UCPel), como Investigadora Auxiliar no Centro de Investigação em Educação (CIEd) da Universidade do Minho, em Braga, Portugal.
} 
a língua inglesa, tem proporcionado aos estudantes maneiras mais rápidas de acessar, de usar jogos, atividades e vídeos, por exemplo. A web auxilia a comunicação real, oportunizando ao sujeito ter interlocutores reais (LEFFA, 2016) surgindo vínculos que possibilitam o acesso a diversas culturas.

As tecnologias digitais também têm colaborado com mudanças na educação, especialmente no que diz respeito às línguas, tanto nos usos da escrita quanto do oral. A partir do contato com sujeitos, onde uma das autoras atuou como professora de língua inglesa, estabelecemos como objetivo deste trabalho é depreender usos de tecnologias digitais em práticas de letramentos com língua inglesa por estudantes do ensino médio.

Pode-se observar que a língua inglesa tem cativado a atenção e o interesse das pessoas, tanto pelo apelo cultural quanto pela necessidade para o mercado de trabalho. Neste trabalho, a língua inglesa não é vista como uma língua estrangeira, e sim como língua adicional, que vem a adicionar ao repertório linguístico do sujeito um novo idioma.

Para tanto, este artigo de cunho qualitativo se justifica, pois nos permite "construir um quadro que vai ganhando forma à medida que se recolhem e examinam as partes" (BOGDAN; BIKLEN, 1994 p. 50), que neste trabalho são compostas por excertos das entrevistas semiestruturadas em grupo, por prints de conversas dos sujeitos da pesquisa.

Os sujeitos participantes fazem parte fazem parte de uma pesquisa maior que busca compreender as práticas de estudantes da educação básica que vivem em contextos plurilíngues sobre aprendizagem de línguas estrangeiras. Nesse artigo, iremos apresentar um recorte sobre o uso da língua inglesa por meio das tecnologias digitais.

A partir de um questionário semiaberto realizado em outubro de 2016, foi feito o levantamento do perfil linguístico de 27 estudantes do ensino médio. A partir das respostas dos questionários, foi possível identificar que quatro estudantes manifestaram um contato maior com as tecnologias digitais em relação à língua inglesa. Esses estudantes, com idades entre 15 e 16 anos, foram convidados a participarem de uma entrevista semiestruturada em grupo. Ao escolherem seus pseudônimos, resolveram optar por nomes que tenham relação com a língua inglesa. Os três primeiros escolheram regiões dos Estados Unidos, e o último utilizou um nick (apelido) que ele usa constantemente em jogos virtuais. Posteriormente, 
dois sujeitos, Ohio e Fox, disponibilizaram prints de conversas realizadas em salas de batepapo dos jogos e em redes sociais, em que eles estabeleceram contato com falantes de outros países utilizando-se da língua inglesa.

Dessa forma, os dados foram analisados a partir do ponto de vista dos sujeitos, bem como a análise escrita dos prints das conversas à luz dos estudos dos letramentos.

\section{Letramentos e Internet}

O contato com as tecnologias digitais tem influenciado nas práticas de letramentos (BARTON; LEE, 2015). Percebem-se mudanças nas maneiras de ler e escrever e também nos ambientes em que as interações ocorrem. Para Barton e Hamilton (2000), os letramentos remetem a práticas sociais, mediadas por textos escritos. Nessa perspectiva, os letramentos abarcam comportamentos - valores, atitudes, sentimentos e relações sociais. Isso inclui a interação entre as pessoas, sem esquecer de ideologias e de identidades. Para Bartlett (2007), os letramentos têm relação com a identidade, ou seja, com o processo social de interação, sendo contínuo, de acordo com as interações vivenciadas.

Dessa forma, é possível destacar eventos e práticas de letramento que se voltam às atividades de leitura e escrita. Inicialmente, para Heath (2000), os eventos de letramento se referem a situações concretas em que a escrita tem papel importante nas relações sociais. Os eventos são ocasiões em que a língua é parte integrante das interações entre os sujeitos e suas estratégias. Já as práticas de letramento, termo proposto por Street (1984), ampliam os usos e significados da leitura e da escrita, incluindo atitudes dos sujeitos nessas práticas. Conforme afirmam Barton e Hamilton (2000), as práticas são maneiras culturais do uso da escrita. Kleiman (2007) destaca que os Estudos de Letramento veem as práticas de letramento como práticas sociais situadas que ocorrem de acordo com as instituições, os sujeitos e as relações de poder existentes de acordo com cada contexto.

Essas práticas formais e dominantes, referem-se, em certas circunstâncias, às práticas leitoras, quando faz uso de um conjunto limitado de textos; representando o cânone, ou seja, um modo concreto de ler e interpretar. Já as práticas vernaculares voltam-se a 
formas de escrita e leituras privadas, em que o sujeito as desenvolve fora do contexto escolar, como as desenvolvidas na internet.

Neste artigo, os letramentos são compreendidos como um conceito plural, pois há letramentos dominantes, valorizados, bem como letramentos vernaculares, sendo práticas não formalizadas (ROJO, 2009). A escola, por sua vez, como agência de letramentos, por vezes, pode excluir determinadas formas de letramentos. Diante da perspectiva dos letramentos, ampliamos o contato com as tecnologias digitais.

Com a crescente presença das tecnologias digitais, os sujeitos passam a interagir por meio dessas tecnologias com pessoas de diversos lugares do mundo, tendo acesso ao conhecimento de formas diferentes. Como ponto inicial, Leffa (2016) descreve que a web auxiliou o contato com a comunicação real. $\mathrm{O}$ acesso às tecnologias digitais possibilita que os sujeitos tenham contato com pessoas de diversos lugares do mundo, podendo aprender outras línguas e acessar a cultura de outros grupos através de sites, jogos, e redes sociais.

Com o surgimento do ciberespaço, surgem novas maneiras de construir saberes, outros meios de aprendizagem, bem como a ampliação do acesso à inteligência coletiva. Já que as tecnologias digitais possibilitam o acesso a várias culturas, Cassany e Hernandez (2012) afirmam que a internet é atualmente utilizada como comunidade de prática, compartilhando os recursos linguísticos de cada sujeito. Nesse viés, a internet tem possibilitado uma construção de componentes emocionais e pessoais, sendo que a leitura e a escrita se tornaram ferramentas para estabelecer vínculos emocionais mais fortes na rede.

De acordo com Cassany (2016), os recursos linguísticos digitais favorecem o aumento do plurilinguismo, ou seja, o acesso a diversas culturas através das línguas adicionais; os recursos linguísticos utilizados on-line; o desenvolvimento de interfaces simples; e, por fim, o uso de aparelhos móveis que permitem o acesso a recursos em tempo e contextos reais. Tais contextos reais de comunicação oferecem avanços em várias áreas de leitura $\mathrm{e}$ escrita digitais. As estratégias empregadas pelos sujeitos para interagir nesses contextos favorecem o ensino e aprendizagem de línguas (CASSANY, 2016).

Tudo isso traz à tona questões de aprendizagem informal e autoaprendizagem (CASSANY; HERNANDEZ, 2012). Benson (2001) destaca isso ao detalhar o fato de que 
aprender uma língua fora do âmbito escolar, como, por exemplo, na internet, possibilita que o sujeito desenvolva determinadas maneiras de tornar a aprendizagem de outra língua oportuna e significativa.

Com o acesso a diversas ferramentas na internet, é possível identificar o desenvolvimento autônomo do sujeito enquanto aprende uma outra língua. Para Bailly (2010), a internet já é uma alternativa (ao invés de ser somente um mero complemento) para as aulas de línguas adicionais. Dessa maneira, a internet é adequada para uma abordagem individualizada em relação a aprendizagem, mas, mesmo individualmente, o sujeito necessita se conectar a outros para aprender. Sendo assim, a autonomia da aprendizagem de línguas não pode ser concebida sem a heteronomia, pois necessita a colaboração e a cooperação dos outros (BAILLY, 2010).

Os jogos aparecem muitas vezes na educação como estratégias de aprendizagem, ou como atividades lúdicas que contribuem para o desenvolvimento dos estudantes. Neste trabalho, abordamos especificamente os jogos online do tipo MMORPG (massively multiplayer online role-playing game), que se caracterizam que se caracterizam por serem jogos de interpretação, e que através da internet, possibilitam a interação de milhares de jogadores, de diferentes países, origens, idades e gênero, por meio da plataforma digital do jogo. Nesse sentido, jogos dessa natureza podem contribuir para o desenvolvimento da língua inglesa.

Os MMORPGs possuem diferentes conteúdos que contribuem para o desenvolvimento da escrita e da leitura. As narrativas do jogo apresentam conteúdos de interação virtual entre jogador-jogo, mas também possibilitam a interação entre jogadores em tempo real, através das salas de bate papo dos próprios jogos. Prensky (2007) destaca que o jogo do tipo MMORPG pode desenvolver diferentes aprendizagens, posto que abarca diferentes conteúdo dentro da dinâmica do jogo, como a necessidade de se criarem estratégias, de tomada de decisão, de interação entre personagens virtuais e reais. O jogo, assim, requer que o leitor/jogador compreenda não apenas a dinâmica do jogo, mas também o idioma, uma vez que o força a participar na elaboração de perguntas e respostas, de feedback e da leitura de regras e instruções. 
Nesse sentido, os conceitos de nativos digitais e residentes digitais (PALFREY; GASSER, 2011) se manifestam de forma mais significativa e nos ajudam a compreender um pouco mais esta relação estabelecida entre os sujeitos e as novas tecnologias. Palfrey e Gasser (2011) definem como nativo digital os sujeitos que possuem potencial para utilizar as tecnologias digitais e desenvolver suas respectivas competências digitais, posto que são indivíduos nascidos na era digital e estão inseridos em uma cultura baseada nos recursos e na disseminação da tecnologia. Entretanto, destacamos que não é possível generalizar todos os nascidos na era digital como nativos digitais, uma vez que as condições econômicas, sociais e culturais influenciam também na interação com as tecnologias.

Por outro lado, os visitantes digitais ou imigrantes são aqueles que aprendem de forma tardia a utilizar as tecnologias digitais. Formados por sujeitos que nasceram anteriormente a era digital, são usuários das novas tecnologias que aprenderam a interagir com a tecnologia de forma mais tardia, mas não necessariamente com maior ou menor eficiência (WHITE; CORNU, 2011).

Nas seções a seguir, discutiremos a aprendizagem de língua inglesa com as mídias na voz dos sujeitos, os quais foram obtidos com a entrevista em grupo; e, por último, analisaremos os prints (capturas de tela) das conversas em redes sociais e jogos virtuais enviadas por Fox e Ohio, reafirmando informações dadas na entrevista.

\section{Uso de língua inglesa com mídias na voz de sujeitos do ensino médio}

$\mathrm{O}$ acesso aos jogos online possibilita que as pessoas interajam com várias pessoas ao redor do mundo, tendo acesso mais rápido à aprendizagem de dúvidas momentâneas que surgem durante a interação com outros jogadores. Os quatro sujeitos explicaram para a entrevistadora, que jogam com frequência, portanto, tornando mais rápido para aprender.

[Excerto 1: Entrevista - grifo nosso]

Entrevistadora: Mas assim, então, vocês falam em inglês nos jogos ou vocês só escrevem?

Louisiana: Mais ou menos.

Ohio: Não! Dá pra falar.

Manhattan: Eu converso. Eu converso com os caras.

Fox: A gente já jogou com americano. 
Ohio: Eu também converso. Eu tenho aquele meu amigo dos Estados Unidos. O Josh. [...] Eu converso com os caras. Eu e o Fox já falamos com ele e tudo. De vez em quando, assim eu erro bastante palavra assim, quando eu não sei, vou pesquisar, mas ele entende. Eu já pedi se eu falo bem. Ele disse que entende bem certo.

Primeiramente, os quatro sujeitos se manifestam nessa conversa afirmando que eles também conseguem falar com os outros jogadores e não apenas escrever. Ohio explica, ao longo da entrevista, que tem um amigo que mora nos Estados Unidos chamado Josh e que além dos jogos eles conversam por outras redes sociais, como o Facebook. Cassany (2012) explica que há uma interação genuína nas práticas vernaculares e que estratégias pessoais são geradas diante do contexto. Gee (2008) destaca, ao falar sobre os jogos, que estes são bons ao utilizar a linguagem dentro de um contexto de diálogo e experiências reais, além de utilizar de imagens e outros tipos de ações. Esses jogos permitem que a linguagem esteja situada, além de dar "informações verbais "just in time", perto do tempo que pode ser usado ou "on demand", quando o jogador sentir necessidade e estiver pronto para isso" (GEE, 2008, p. 36). Os dados indicam que Ohio, a partir de seu interesse pessoal, pesquisa as expressões que ele não conhece, para que a interação fique mais situada e se efetive. Por ser um conhecimento prático cotidiano, o sujeito dá mais sentido ao que ele quer e a língua é vista como função, segundo Leffa (2016) e não apenas como sistema.

Quando perguntado aos sujeitos se eles consideram mais fácil aprender na internet, o sujeito Ohio deu a seguinte resposta:

\section{[Excerto 2: Entrevista - grifo nosso]}

Ohio: É mais fácil pra tu aprender, porque é mais fácil pesquisar o que tu quer.

Neste excerto, percebe-se que para Ohio, a internet proporciona maior facilidade para aprender uma outra língua, por pesquisar temas de seu interesse. Conforme Cassany e Hernandez (2012) descrevem, os jovens leem e escrevem voluntariamente procedimentos particulares e de seu interesse, ou seja, o fato de ser uma atividade espontânea, com situações reais de comunicação, a partir da internet, favorecem a aprendizagem da língua inglesa, havendo maior sentido no modo como se comunicam. 
Assim, compreendemos, nesses primeiros excertos, que Ohio destaca diferentes percepções do aprender dentro do ambiente escolar e do aprendizado ocorrido fora do ambiente escolar, na internet. A realização de uma tarefa espontânea faz Ohio se considerar insider (Gee, 2001) dentro do ambiente virtual.

Coscarelli (2017, p. 69) ressalta que "A internet possibilita uma movimentação mais livre entre os textos e as fontes de informação por parte do leitor, que acaba construindo, com as escolhas, o percurso de leitura". Entretanto, ressaltamos que apesar das facilidades proporcionadas pelas TICs, o professor e o ambiente escolar podem proporcionar ao estudante caminhos para saber avaliar as leituras, para fazer escolhos e orientar nessas buscas (COSCARELLI, 2017).

Em continuação, os sujeitos também expõem que:

\section{[Excerto 3: Entrevista - grifo nosso]}

Manhattan: É porque na escola, na escola tem a distração que tem os amigos, tem só duas aulas, são uma horinha e meia no máximo, e no computador tu fica o quê? Cinco horas direto, jogando o mesmo jogo em inglês.

Ohio: $\mathrm{Na}$ aula tu aprende, por exemplo, a mesma coisa em três, quatro aulas e em casa tu pode aprender a mesma coisa em uma, duas horas.

Fox: E também a gente fica entretido jogando jogo em inglês, a gente fica focado lá e a gente acaba aprendendo mais rápido.

Inicialmente, para Manhattan a escola, além de ter poucas aulas de inglês, há distrações, como por exemplo, os amigos. Há indícios, neste trecho, que o sujeito é consciente do pouco tempo disponibilizado para a aprendizagem de línguas, e dos desafios e limitações da escola, diante do currículo institucionalizado e da pouca carga horária destinada as línguas estrangeiras. Ohio sita a morosidade para a aprender um conteúdo.

Considerando que no Brasil há somente duas aulas semanais no Ensino Médio, os estudantes percebem as dificuldades em dar continuidade nas atividades e nos conteúdos em virtude dos desafios do ensino público. Já em casa, eles consideram que a pesquisa e a interação com falantes da língua inglesa, proporcionam o conhecimento de determinado assunto em menor tempo. Fox confirma a ideia dos colegas, usando a palavra entretido, ou seja, a pessoa mantém um foco naquilo que é de seu interesse. De acordo com Lévy 
(1997), a noção de tempo e espaço é transformada diante das tecnologias digitais. Com isso, Bailly (2010) afirma que on-line, as pessoas podem assumir papéis mais centrados enquanto comunicadores, do que na dimensão da identidade de serem estudantes.

Outro aspecto que observamos na fala dos sujeitos é a aprendizagem autodirigida, uma vez que essa se caracteriza pela produção por parte dos estudantes, de sua própria aprendizagem, ao invés de simplesmente consumirem ensinamentos (HOLEC, 1998). Os estudantes destacam em suas falas, aspectos que remetem à liberdade de aprender em seu próprio ritmo e de forma interativa através dos jogos, diferentemente do aprendizado em sala de aula, onde relacionam as aulas a um ensinamento mais estruturado e lento.

Os sujeitos trazem as informações para situações reais de comunicação, sendo um conhecimento prático cotidiano (CASSANY; HERNANDÉZ, 2012). Nessa interação com sujeitos reais, os estudantes se entretêm não apenas com o aprendizado da língua inglesa, mas com modos de interação com o outro, em vez de atividades repetitivas como destacadas por Ohio, que poderiam ser realizadas de forma mais rápida e interativa. Bailly (2010) confirma esta ideia ao afirmar que, em virtude da internet, o contato com outras pessoas e até mesmo com línguas adicionais tornou-se mais fácil, mais barato e menos demorado, além de exigir menos esforço para entrar em contato com outras pessoas de diversos lugares do mundo. A partir das interações sociais, há a inteligência coletiva, que conforme descrito por Lévy (2009), volta-se à interação com o coletivo a partir de redes sociais, comunidades, blogs e jogos.

Ademais, os estudantes destacam o aprendizado e uso de expressões coloquiais de interação, utilizados nas conversas orais e escritas que eles têm com pessoas de outros países em jogos e nas redes sociais. Os sujeitos mencionam o uso frequente de abreviações e gírias, que muitas vezes não são privilegiadas no ensino escolar, incluindo também aspectos sobre a escrita formal de verbos auxiliares que são aprendidos na escola e que não são usados nas redes sociais.

Nesse sentido, os estudantes percebem que a escola não privilegia o ensino dessas expressões, consideradas coloquiais. A escola irá ensinar a norma padrão, enquanto a internet irá proporcionar uma complementação dessa aprendizagem. 
[Excerto 4: Entrevista - grifo nosso]

Ohio: Quando eu converso com o Josh, ele usa muita abreviação. You (você) ele só bota U, aí I don't know (eu não sei) é IDK. Tudo assim, abreviado.

A partir do excerto 4, os sujeitos situam que os norte-americanos são os que mais usam gírias em relação aos outros contextos que tiveram contato. Com a interação descrita por Ohio, é possível confirmar o uso de gírias a partir dos prints das conversas enviadas por Ohio e Fox, depois das entrevistas, e que serão mais detalhadas na seção a seguir.

Outro fator interessante observado é a relação que os quatro estudantes fazem com a língua portuguesa, ao interagirem com outras pessoas, bem como a importância do inglês aprendido na escola com as atividades vernaculares utilizadas por eles por meio da internet.

[Excerto 5: Entrevista - grifo nosso]

Manhattan: Na escola é praticamente essencial ter. Porque se tu não tiver um computador, um celular, tu não vai aprender em lugar nenhum. Tem que ter na escola.

Ohio: Porque geralmente tu não vai pegar um dicionário e aprender com um dicionário inglês, por exemplo.

Fox: Mesmo se tu tem o computador e tals e joga bastante e aprende inglês que nem eu fiz, sempre é bom ir na escola, porque de vez em quando eu sempre aprendo uma coisinha ou outra lá a mais.

Ohio: Tipo, geralmente verbo essas coisas tu não aprende muito em jogo, tu aprende, tipo no jogo é mais direto assim. Agora na escola tu aprende mais por parte, porque daí é bom.

Fox: Tipo, regras e tals.

Entrevistadora: Vocês acham que é essencial por causa das regras...

Ohio: É, é bom pra escrita se tu vai ver. Porque no jogo vai ser mais o áudio que tu vai escutar assim, mas na escola é bom por causa da escrita.

Manhattan: É, na maioria das vezes a pessoa que tá contigo não vai falar o formal, né? Daí tu tem que aprender, né? É que nem eu, não vou falar com uma pessoa toda certinha (referindo-se à língua) no computador o português com ela, que nem eu acho que ela vai fazer comigo no inglês.

Manhattan reforça o uso das tecnologias digitais, quando menciona a questão do uso do celular e do computador. Apesar das tecnologias digitais favorecerem o acesso às línguas, a escola se torna ponto de interação e também mediação de acordo com a fala de Ohio. A necessidade da interação com outra pessoa para a aprendizagem da língua inglesa, segundo Bailly (2010), facilita e motiva o aluno a querer saber mais sobre ela.

Quanto a Fox, ele associa que aprendeu língua inglesa por meio dos jogos. Ele também considera, assim como os colegas, que a aprendizagem de língua inglesa na escola é 
essencial, afirmando que eu sempre aprendo uma coisinha ou outra lá a mais. Para ele, o uso da língua inglesa se torna importante na escola, pois pode ajudar com o que ele utiliza na internet. Mas a expressão uma coisinha ou outra lá a mais, demonstra que o diminutivo define o que para o sujeito é considerado menor em aprendizagem, frente ao campo de informações que ele presencia na internet (BAILIY, 2010). A utilização da expressão $a$ mais também firma a opinião dele, em relação ao contato da língua com o ciberespaço, levando em conta que há um universo de informações, bem como uma grande quantidade de pessoas interagindo (LÉVY, 1998).

Os sujeitos afirmam que a escola proporciona o acesso a aprendizagem de verbos, dizendo que na internet é mais direto devido à comunicação diante do contexto. Acaba se tornando uma via de mão dupla; a escola colabora com o uso do inglês na internet e a internet favorece no aperfeiçoamento e aprendizagem em sala de aula. Cassany (2012) esclarece que seria importante aproximar as práticas vernaculares e as práticas dominantes, que muitas vezes a escola não reconhece o que é feito fora dela, sendo que haveria uma gama de novas informações que poderiam ser aproveitadas A escola é vista, pela ótica dos estudantes, novamente como formal, mediante as conjugações e regras, além de explicar por assuntos ou partes, como Ohio descreve. É possível entender, dessa forma, que os sujeitos se consideram insiders (GEE, 2001) dentro do ambiente virtual.

Novamente fica claro na voz dos sujeitos, a importância de visualizar a escola e a internet como complementos. Se na escola eles aprendem “os verbos”, são através dessas estruturas ensinadas que eles conseguiram elaborar as sentenças para se comunicar em língua inglesa. Assim, a escola poderia partir das práticas informais para apresentar as diferenças para a norma padrão.

Em seguida, Ohio complementa que no jogo "vai ser mais o áudio" "mas na escola é bom por causa da escrita". O acesso aos jogos que os sujeitos utilizam é mais direto, através de conversas de áudio com os outros users. Já a escola é percebida como ponto principal para o conhecimento da língua escrita.

Manhattan traz sua realidade afirmando que ele também não vai conjugar todos verbos, ao utilizar a língua portuguesa em uma comunicação através das mídias digitais. O 
fato de abreviar traz um novo marco para a escrita, pois são utilizados novos recursos para se comunicar nessa outra língua. Dessa forma, eles associam que a aprendizagem da língua inglesa na escola é essencial para que o sujeito consiga utilizar as regras em contextos mais formais, com a necessidade de ter conhecimento disso.

Depreendemos a partir dos dados, que os estudantes destacam alguns aspectos sobre o ensino da língua inglesa dentro do ambiente escolar, muitas vezes caracterizando esse aprendizado como desvinculado das práticas sociais do sujeito, quando ele indica que fora do ambiente "formal", muitas vezes as normas cultas abordadas na escola não serão necessárias, como em conversas informais nos jogos online. Assim, esses estudantes associam o aprendizado escolar do idioma a uma identidade "legal da escola" (CASSANY; HERNÁNDEZ, 2012) onde o assunto não se conecta ou não se dá tamanha atenção a diferentes aspectos dos valorizados dentro desse ambiente educativo. Para os estudantes, esse tipo de aprendizagem se torna mecânica e sem sentido, uma vez que necessitam utilizar de procedimentos padrões predefinidos.

Por outro lado, a compreensão do que ocorre na internet é vista de forma diferente e contextualizada com a realidade desses estudantes. Conforme vimos anteriormente, o aprendizado de gírias e expressões idiomáticas não ocorrem dentro do ambiente escolar, mas os estudantes destacam a importância destas para se comunicar no "mundo real". Assim, compreendemos que os jovens leem e escrevem voluntariamente gêneros discursivos próprios com procedimentos particulares e com o capital linguístico de seu interesse. Além disso, os jovens usam a internet compartilhando os recursos linguísticos em interações de comunicação reais, através das redes sociais e de outros mecanismos de comunicação disponíveis (CASSANY; HERNÁNDEZ, 2012).

Por fim, os sujeitos demonstram o contato com a língua inglesa na internet e a necessidade do cuidado com o uso do tradutor na utilização da língua inglesa.

[Excerto 6: Entrevista - grifo nosso]

Entrevistadora: Vocês acham o tradutor muito importante?

Grupo: Não.

Ohio: Ele dá a tradução errada.

Fox: Na verdade é ruim pra traduzir também, né. 
Manhattan: Só se for pra pegar e tu monta...

Entrevistadora: Mas por quê?

Ohio: Não, porque geralmente assim, se tu for colocar uma palavra que tu sabe assim, o tradutor joga de outro jeito, às vezes ele traduz errado, tipo de forma errada, a palavra errada dependendo como.

Fox: É, assim, eu não lembro a frase assim, mas eu lembro que quando eu botei no tradutor eu mesmo vi que ele traduziu errado. Aí eu botei do jeito certo depois.

Ohio: É bom pra palavra separada para tu aprender tipo, quando eu não sei uma palavra eu pesquiso no tradutor.

Para os sujeitos, o uso do tradutor é importante quando se trabalha com as palavras separadas. De acordo com a opinião deles, é possível identificar a familiaridade dos sujeitos com a língua inglesa novamente, pois eles perceberam o erro no tradutor e corrigiram a maneira de escrever. Essa consciência sobre estrutura e sobre as falhas do tradutor, podem ser possibilitadas pela escola. Os estudantes percebem, que essas variações são possíveis através dos seus conhecimentos de estrutura e regras, que como anteriormente apresentados ocorrem dentro do ambiente escolar. Cassany (2010) explica que todas as línguas apresentam variações, "todos os membros de uma comunidade linguística não falam, nem escrevem da mesma forma, nem utilizam a língua do mesmo modo nas diferentes situações comunicativas $^{1 “ “}$ (p. 32-33, tradução nossa). Nesse sentido, a percepção dos estudantes quanto ao uso do tradutor, demonstra que estes entendem que, assim como o dicionário, o tradutor possibilita apenas uma tradução mecânica das palavras, sem as devidas interpretações, conjugações e inferências características de cada grupo e língua.

Na próxima seção apresentaremos os prints enviados pelos estudantes que confirmarão a interação e aprendizagem de língua inglesa em um espaço informal.

\section{Análise dos prints das conversas em língua inglesa}

Assim como foi possível observar ao longo da entrevista o posicionamento dos estudantes quanto à aprendizagem da língua inglesa fora do âmbito escolar, podemos tam-

1 “ [...] todos los miembros de la comunidad lingüística no hablan ni escriben de la misma forma, ni tamtpoco utilizan la lengua del mismo modo en las diferentes situaciones comunicativas". 
bém observar de que forma a utilização da língua ocorre nos ambientes informais, proporcionando não apenas um aprendizado, mas possibilitando a prática e construção de outras atitudes atribuídas à língua pelos sujeitos.

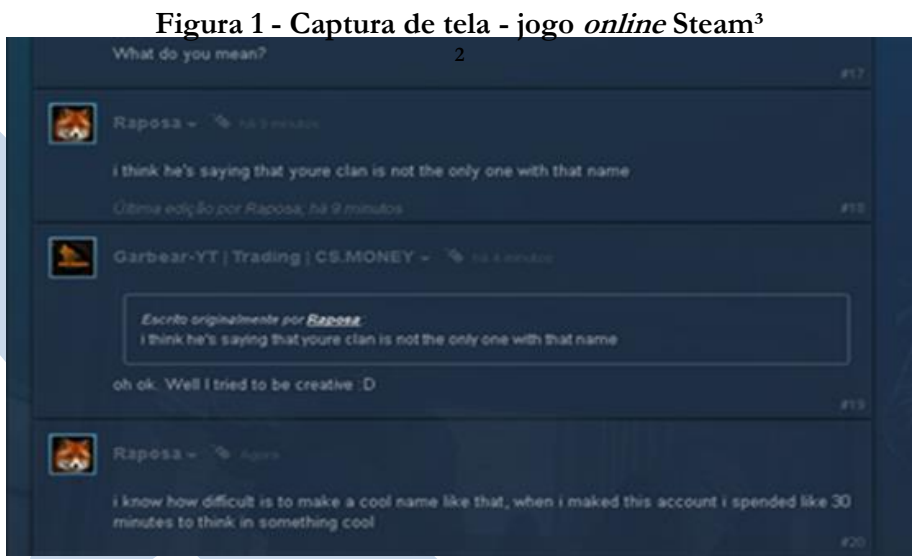

Fonte: Disponibilizado pelos sujeitos

No print, é possível destacar que os jogadores fazem parte de um clã virtual a partir de uma comunidade chamada Steam ${ }^{3}$. Ela é uma plataforma definitiva de entretenimento onde é possível jogar, conversar e desenvolver diversas atividades. Fox que está no jogo com o nickname de Raposa, conversa com outro jogador a respeito da criação do nome do clã de um jogo em específico.

É possível depreender, a partir do contexto de maneira geral, que Fox não apenas entende o bom funcionamento do jogo, como também da língua inglesa, mesmo que cometa falhas no uso da língua, ao longo de sua comunicação, como quando conjuga os verbos "make" e "spend" de forma errônea. Observa-se que apesar de pequenas falhas gramaticais, a comunicação ocorre de forma bem-sucedida, auxiliando o jogador Garbear-Y'T a

${ }^{2}$ Garbear - YT: - What do you mean? Raposa: - I think he's saying that youre clan is not the only one with that name. Garbear: - Oh ok. Well I tried to be creative :D. Raposa: - I know how difficult is to make a cool name like that, when I maked this account I spended like 30 minutes to think in something cool.

${ }^{3}$ http://store.steampowered.com/ 
executar a função até então por ele pretendida. Gee (2008) destaca que a aprendizagem, envolve, no aluno, o sentido de domínio e agenciamento sobre o conteúdo, desenvolvendo a habilidade de produzir e não apenas reproduzir o que fora aprendido.

$\mathrm{Na}$ figura a seguir (2), podemos novamente visualizar Fox e Garbear-YT conversando, porém agora com outros jogadores: Commie Dog e Thommii Chan. Nesse caso, a linguagem informal, tida como vernacular por Cassany (2010), aparece também nas capturas de tela de uma rede social. Assim, podemos observar não apenas os usos da língua inglesa em diferentes ambientes online, mas também que muitas relações estabelecidas, em jogos online, ultrapassam o jogo e passam a constituir relações em outras plataformas.

Com isso, as conversas migram e o uso da língua inglesa se torna ainda mais presente e necessário. Para Cassany (2012), os estudantes aprendem outros recursos linguísticos de maneira informal e eles fazem trocas uns com os outros, aprendendo a língua em questão. Por serem comunicações autênticas, os sujeitos veem mais sentido em aprender a língua.

Nesse segundo diálogo estabelecido entre os jogadores, é possível considerarmos novamente a colaboração entre os jogadores, em se auxiliarem no aprendizado da língua inglesa, e interagindo informalmente. É possível destacarmos também o uso de expressões informais como "comrade", "bit me up" e "bit". Conforme anteriormente destacado pelos estudantes, essas expressões informais caracterizam-se por não fazerem parte do currículo formal escolar, mas ao convívio diário em conversas e ambientes informais, reforçando o argumento dos estudantes de que muitas vezes a aprendizagem fora do ambiente escolar acaba por ter uma contextualização mais aproximada de suas necessidades. 
Figura 2 - Captura de tela do jogo 2 - jogo online - Steam ${ }^{4}$

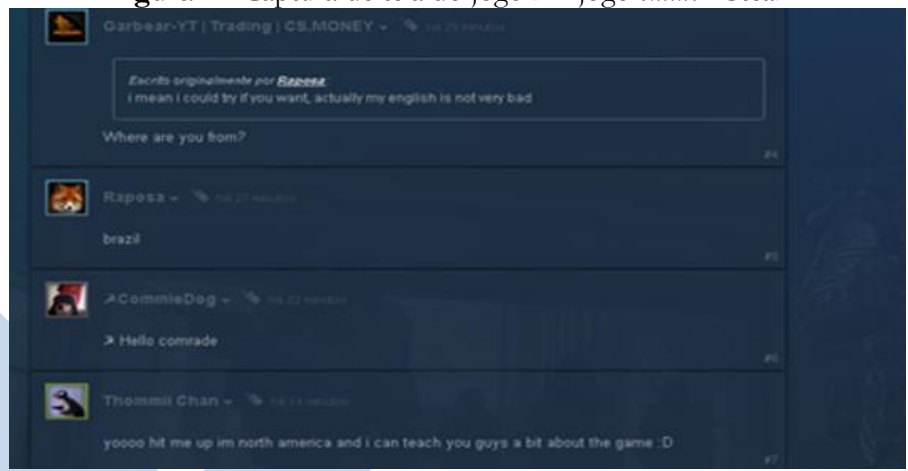

Fonte: Disponibilizado pelos sujeitos

Podemos destacar ainda, as características desses sujeitos interagindo, como nativos digitais que não apenas acessam as redes, mas desenvolvem habilidades para interagir com essas novas tecnologias. Os jogadores, demonstram interagir através de diferentes mídias, com a experiência do jogo, bem como através das redes sociais e das salas de batepapo das quais participam. Eles transitam entre as diferentes tecnologias, utilizando diferentes plataformas digitais, como o computador e a conexão na internet, para estabelecer contatos via salas de bate papo e até mesmo jogos online, desenvolvendo o mesmo nível de contato e domínio sobre elas. Essas ferramentas possibilitam não apenas o desenvolvimento das habilidades com as tecnologias digitais.

Nos prints a seguir do Facebook, Ohio é o sujeito que conversa em azul. Novamente podemos observar o uso de expressões coloquiais como "a sec", "bro", "bud” e a cooperação dos jogadores interagindo, agora em uma rede social. Os sujeitos utilizam da rede social e do seu conhecimento em língua inglesa, para superar uma dificuldade encontrada no jogo. Assim, a língua é utilizada como meio de auxilio, e aspectos linguísticos são mobilizados com o intuito de facilitar a compreensão e ajudar na resolução do problema detectado.

\footnotetext{
${ }^{4}$ Raposa: - I mean i could try if you want, actually my English is not very bad. Garbear: - Where are you from? Raposa: - brazil. CommieDog: - Hello comrade. Thommii Chan: - yoooo hit me up in north America and I can teach you guys a bit about the game :D.
} 
Figura 3 - Captura de tela do Facebook 1

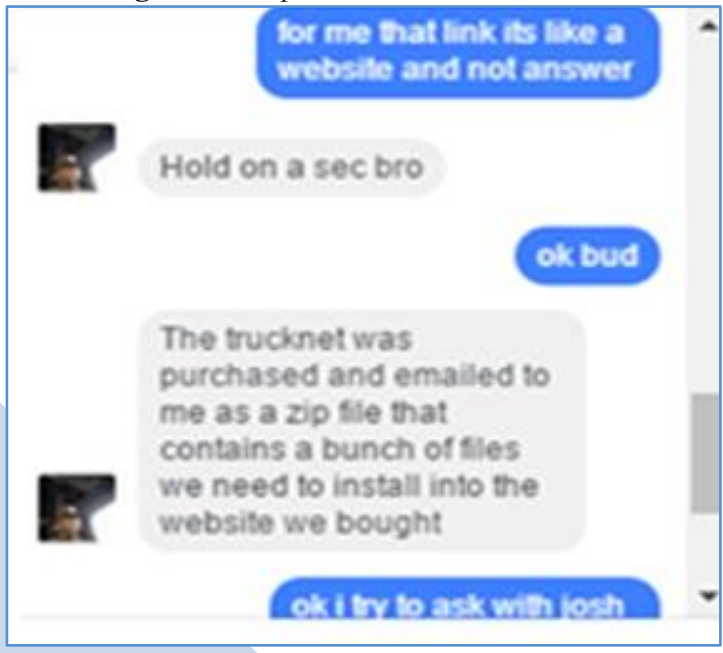

Fonte: Disponibilizado pelos sujeitos

Outro fator importante é o vínculo de amizade que surge por meio dos jogos online. O sujeito fortalece o vínculo por meio de redes sociais que permite que as pessoas entrem em contato com informações reais e pessoais a respeito das outras. Cassany (2012) traz que o contato a partir da leitura e da escrita pela internet auxilia na construção e identidade social e estabelece vínculos emocionais.

Dessa forma, muitas vezes, o desinteresse do aluno pode ser observado como um conflito de identidades leitoras. A leitura e a escrita realizadas dentro do ambiente escolar para este aluno, é compreendida como um fenômeno socialmente construído, mas as leituras e escritas que são privilegiadas dentro desse ambiente, o escolar, muitas vezes não estão relacionadas à identidade dos estudantes.

Os usos sociais da leitura e da escrita são atividades articuladas com as rotinas desses sujeitos, das duas respectivas vidas sociais e dos relacionamentos interpessoais por eles estabelecidos. Nessa perspectiva, as atitudes dos sujeitos a respeito da língua e às atividades a ela relacionados estão ligados a esses anseios e decepções, variando de pessoa para pessoa (ALIAGAS; CASTELLÀ; CASSANY, 2009). 
$\mathrm{Na}$ figura a seguir (4), podemos novamente observar a mobilização do capital linguístico associado aos conhecimentos prévio do jogo para estabelecer uma comunicação. Novamente abreviações e outros aspectos informais são identificados. Entretanto, como anteriormente, a comunicação consegue se efetivar de forma adequada entre os dois indivíduos.

Figura 4 - Captura de tela do Facebook $2^{5}$

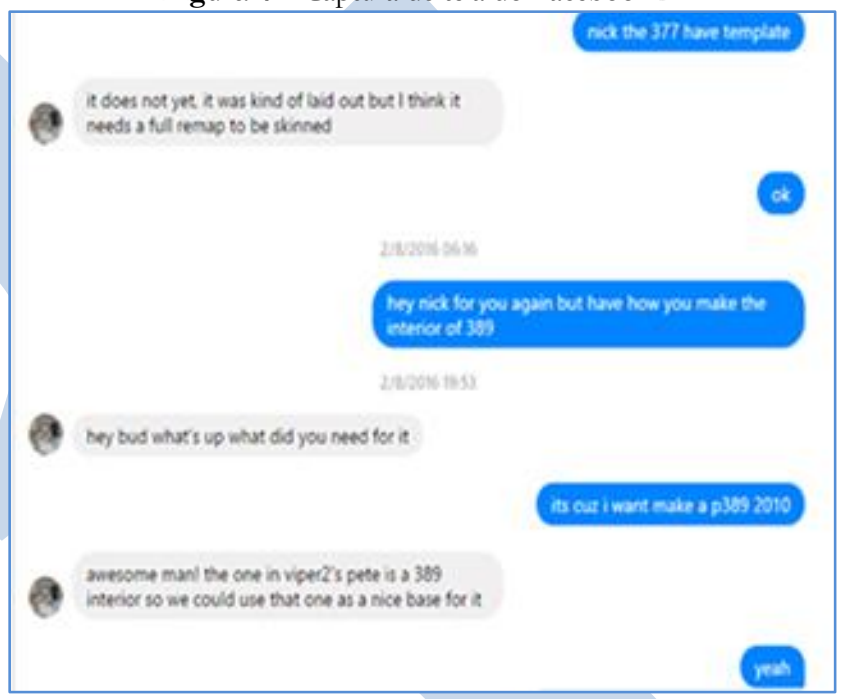

Fonte: Disponibilizado pelos sujeitos

$\mathrm{Na}$ figura anterior (4), ocorrem novamente algumas falhas gramaticais, como na frase nick the $\mathbf{3 7 7}$ have template. Porém, contemplamos também que a comunicação entre os dois sujeitos não é prejudicada.

Tori (2010, p. 218) destaca que "o cérebro dos nativos" se desenvolveu de forma diferente em relação às gerações pré-internet”, pois eles conseguem mobilizar diferentes saberes e interagir com as tecnologias de forma a desvendar o que ainda não sabem, e

\footnotetext{
${ }^{5}$ A: - Nick the 377 have template. B: - it does not yet, it was kind of laid out but I think it needs a full remap to be skinned. A: - Ok. Hey nick for you again but have how you make the interior of 389. B: - hey bud what's up what you did for it. A: - its cuz I want make a p389 2010. B: - awesome man! The one in viper2's pete is a 389 interior so we could use that one as a nice base for it. A: - yeah.
} 
construir novos aprendizados. Nesse sentido, a língua inglesa, utilizada na maior parte dos jogos online e nos fóruns desses jogos, torna-se o meio pelo qual esse aprendizado ocorre.

$\mathrm{Na}$ figura 4, identificamos como essa interação de aprendizado e de mobilização dos conhecimentos ocorre através da língua inglesa, e tal como em uma conversa informal, notamos a presença de expressões coloquiais como “bud” ou “cuz”, que normalmente não são associadas ao aprendizado da língua inglesa em um ambiente escolarizado e formal. Enquanto o aprendizado no nível acadêmico é visto como um processo estruturado e que, muitas vezes, não abarca os saberes sociais do mundo externo à escola, as aprendizagens no ambiente virtual são vistas como fluídas e naturais. "Eles [os nativos] gostam de jogos, estão acostumados a absorver (e descartar) grande quantidade de informações, a fazer atividades em paralelo, precisam de motivação e recompensas frequentes, gostam de trabalhar em rede e de forma não linear" (TORI, 2010 p. 218), possibilidades que são encontradas de forma mais recorrente no ambiente virtual.

Nesse sentido, podemos constatar na Figura 5, como os estudantes conseguem estabelecer a interação com os outros jogadores, mobilizando outras formas de contato além da sala de bate-papo do jogo. Utilizando as redes sociais, os jogadores demonstram uma interação além do jogo, uma certa intimidade na forma de se comunicar e interagir.

Depreendemos, então, que as atitudes dos sujeitos perante a linguagem contribuem também para a consolidação de uma relação entre os jogadores, trazendo sentidos atrelados a questões emocionais e afetivas. Além disso, podemos observar o uso vernacular da língua americana, repleto de gírias, abreviações e expressões casuais. Uma linguagem, diferente da desenvolvida e trabalhada dentro do ambiente escolar, quando abordada a língua inglesa. 
Figura 5 - Captura de tela do Facebook 3

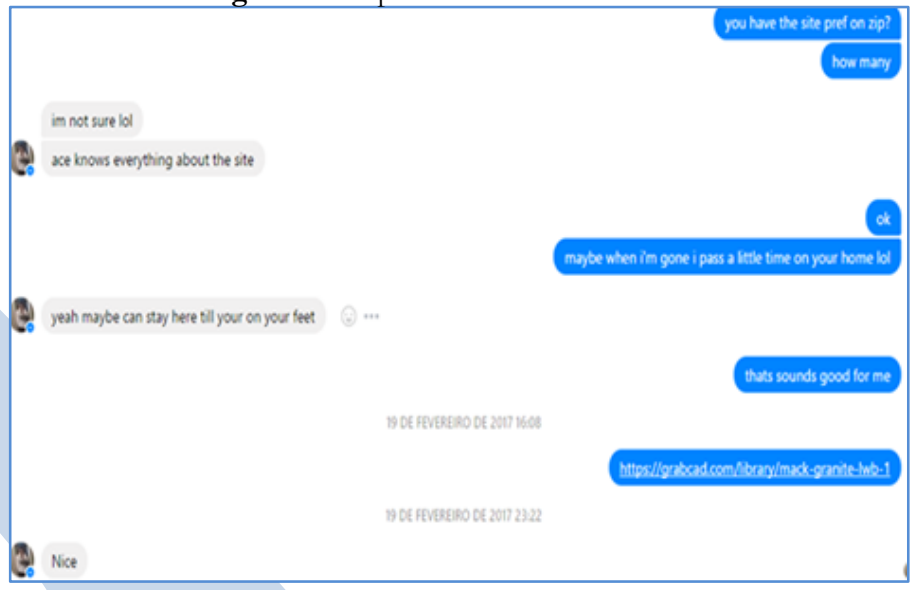

Fonte: Disponibilizado pelos sujeitos

Reforçamos que fica explicito o interesse dos estudantes e a possibilidade de uma prática que avança para além dos temas e conteúdos abordados na escola. Essa mesma prática, distancia-se também das exigências formais da escrita acadêmica do meio universitário, onde estes estudantes em breve ingressarão.

Relacionando os usos sociais da língua inglesa pelos estudantes com suas respostas às entrevistas anteriores, verificamos que esses usos contribuem para a consolidação dos sentidos que eles atribuem à língua: dentro da escola, um processo formal e descontextualizado da realidade à qual eles pertencem; fora da escola, nos ambientes virtuais, é uma língua flexível que possibilita o aprendizado de forma dinâmica e interativa, e onde conseguem desenvolver novos conhecimentos e práticas compatíveis com a realidade à qual estão inseridos.

Entretanto, destacamos que o aprendizado da língua inglesa com o uso das tecnologias digitais por estes estudantes, fez-se de forma concomitante ao ensino e à aprendizagem desenvolvidos nas aulas de língua inglesa. Nessa perspectiva, não se torna possível atribuir o aprendizado a um ou a outro contexto isoladamente, mas talvez a consonância entre os saberes escolares e a possibilidade de prática com falantes nativos, através das 
redes sociais e dos jogos online, seja a grande desencadeadora dos conhecimentos construídos.

\section{Considerações Finais}

Os jogos e as redes sociais vieram fortalecer o mundo digital, possibilitando não apenas o contato com as línguas adicionais, mas também interligando pessoas e jogadores de diferentes partes do mundo. As tecnologias digitais, possibilitaram aos estudantes de língua inglesa acesso a um vasto número de textos digitais em língua adicional.

A leitura na internet tem acentuado a necessidade e a importância de se adotar, cada vez mais, um papel crítico e ativo na interpretação dos textos encontrados. Em acréscimo, tem marcado a importância de compreender quais as fontes confiáveis e como articular o domínio da língua adicional para se inserir nesse ambiente. Além desses enfoques, ainda, tem oportunizado o desenvolvimento de estratégias que possibilitem identificar problemas, localizar e selecionar as informações (VALERO; VÁZQUEZ; CASSANY, 2015).

Para os estudantes de línguas adicionais, surgem ainda outros desafios, como desenvolver a competência linguística no aspecto vernacular. Muitas vezes, dentro do âmbito escolar e acadêmico, o idioma oficial e todas as suas normas são, não apenas reconhecidos, mas são a única forma aceita (CASSANY, 2010). Entretanto, nos ambientes informais, como as redes sociais e os jogos de MMORPG, que permitem a interação de culturas e de pessoas de todas as partes do mundo, nem sempre se fazem presentes.

Ao inserir-se em práticas que possibilitam contatos instantâneos promovidos pelas novas tecnologias, os estudantes aprendem como mobilizar os conhecimentos linguísticos aprendidos dentro da escola e fora dela, passando a construir novos sentidos.

Enquanto na escola a comunicação é vista como uma obrigação a ser cumprida, associada a práticas descontextualizadas ou repetitivas, como realizando tarefas ou conjugando verbos; no ambiente virtual, a comunicação é vista como uma ampla possibilidade de aprendizado, interação, sem restrições ou exigências prévias relativamente a padrões formais unicamente. 
Pahl e Rowsell (2005) sugerem a necessidade de construir pontes entre as línguas vernaculares utilizadas pelos estudantes nos ambientes informais, como as redes sociais e as salas de bate-papo e as línguas oficiais que permeiam o ambiente acadêmico. Nesse sentido, destacamos a importância de levar para a escola essas outras práticas de outros contextos dos estudantes, para que juntamente com o aprendizado da língua inglesa, ocorram práticas que reforcem as atitudes do sujeito a respeito da língua inglesa.

Nesse sentido, compreendemos que as tecnologias digitais podem contribuir para o desenvolvimento da língua inglesa, e que elas devem atuar de forma a contribuir com o aprendizado que já ocorre dentro da sala de aula. Nossos dados apontam que a utilização das novas tecnologias digitais, inclusive das redes sociais e dos jogos online, podem ser poderosos aliados dos professores dentro de sala de aula, como forma de interação e contextualização dos temas e tópicos abordados, bem como complementos à prática da língua inglesa pelos estudantes.

Assim, como afirma Gee (2001), é necessário refletir sobre uma aprendizagem que esteja relacionada com o que ocorre dentro e fora da escola, identificando o que há de melhor nos bons jogos e que estimulam tanto os estudantes a querer entrar em contato com outras línguas.

\title{
USES OF DIGITAL TECHNOLOGIES IN LITERACY PRACTICES IN ENGLISH BY HIGH SCHOOL STUDENTS
}

\begin{abstract}
Digital technologies are daily in people's lives and have been contributing to learning other languages. The aim of this paper is to understand the use of digital technologies in English language literacy practices by high school students. Through social network screenshots and game chat, as well as semi-structured group interviews. It was possible to analyze interactions of high school students with colleagues from other countries, positions about the use of English in and out of school, as well as evidence of school conditions of English language teaching. Data analysis is based on approaches to literacy studies and digital technologies, which recognize the value of new technologies not only in the classroom but also in vernacular practices. For the research subjects, learning that takes place within the virtual environment, specifically in online games, is characterized as autonomous and interactive, while classroom practices are perceived as providing the opportunity to learn standard English writing. However, although students point to the school and the internet as distant, subjects do not deny the school's contributions to English language learning, but do not establish a link between vernacular online gaming practices and dominant school practices.
\end{abstract}

KEYWORDS: Internet, online games, English language. 


\section{REFERÊNCIAS}

ALIAGAS, Marin C.; CASTELLÀ, Josep Maria.; CASSANY, Daniel. “Aunque lea poco, yo sé que soy listo. Estudio de caso sobre un adolescente que no lee literatura", en Revista Ocnos, n. 5, 2009, p. 97-112.

BAILLY, Sophie. Supporting Autonomy Development in Online Learning Environments: What Knowledge and Skills do Teachers Need? In: VILLANUEVA, M.; RUIZ, M.-N.; LUZON, J. (Ed.) Genres Theory and New Literacies: Applications to Autonomous Language Learning. Cambridge: Cambridge Scholars Publishing, 2010.

BARTLETT, Lesley. To seem and to feel: situated identities and literacy practices. Teachers College Record, Columbia University, v. 109, n. 1, p. 51-69, january 2007.

BARTON, David; HAMILTON, Mary. Literacy practices. In: Barton, David. et al. Situated literacies: reading and writing in context. London: Routledge, 2000.

BARTON, David; LEE, Carmen. Linguagem online: textos e práticas digitais. São Paulo: Parábola Editorial, 2015.

BENSON, Phil. Teaching and Researching Autonomy in Language Learning. Harlow: Longman/Pearson Education, 2001.

BOGDAN, Robert; BIKLEN, Sari. Investigação Qualitativa em Educação: uma introdução à teoria e aos métodos. Porto: Porto Editora, 1994.

CASSANY, Daniel. "Leer y escribir literatura al margen de la ley", en CILELIJ [I Congreso Iberoamericano de Lengua y Literatura Infantil y Juvenil]. Actas y Memoria del Congreso. Madrid: Fundación SM / Ministerio de Cultura de España. 2010. p. 497-514.

; HERNÁNDEZ, Denise. ¿Internet: 1; Escuela: 0?. CPU-e, Revista de Investigación Educativa, 14, enero-junio 2012.

COSCARELLI, Carla Viana. A leitura em múltiplas fontes: um processo investigativo. Ens. Tecnol. R., Londrina, v. 1, n. 1, p. 67-79, jan./jun. 2017.

GEE, Jean Paul. Progressivism, critique, and socially situated minds. In C. Dudley Marling and C. Edelsky, eds, The fate of progressive language policies and practices. Urbana, IL: NCTE, 2001.

. Learning and games. In: The ecology of games: conencting youth, games, and learning. Foundation Series on Digital Media and Learning. Cambridge, MA: The MIT Press, 2008.

HEATH, Shirley Brice. What no bedtime story means: narrative skills at home and school. In: Duranti, A. (Org.) Linguistic anthropology: a reader. Oxford: Blackwel, 2001.

HOLEC, Henri. L’apprentissage autodirigé: une autre offre de formation. Le Français dans le Monde, juin. 1998. 
KLEIMAN, Ângela. Professores e agentes de letramentos: identidade e posicionamento social. Revista Filologia e Linguística Portuguesa, n. 08, 2007. p. 409-424.

LEFFA, Vilson. Redes sociais: ensinando línguas como antigamente. In: ARAÚJO, J.; LEFFA, V. Redes sociais e ensino de linguas. São Paulo: Parábola Editorial, 2016.

PAHL, Kate; ROWSELL, Jennifer. Literacy and Education: Understanding the New Literacy Studies in the classroom. London: Paul Chapman Publising/SAGE Publications Company. 2005.

PALFREY, John; GASSER, Urs. Nascidos na era digital: entendendo a primeira geração dos nativos digitais. Porto Alegre: Artmed, 2011.

PRENSKY, Marc. Digital game-based learning. St. Paul: Paragon House Edition, 2007.

ROJO, Roxane. Letramentos múltiplos, escola e inclusão social. São Paulo: Parábola. Editorial, 2009.

STREET, Brian. Literacy in theory and practice. Cambridge: Cambridge University Press, 1984.

TORI, Romero. Educação sem distancia: as tecnologias interativas na redução de distância em ensino e aprendizagem. São Paulo: Editora Senac São Paulo, 2010.

VALERO, Maria José; VÁZQUEZ, Boris; CASSANY, Daniel. Desenredando la web: la lectura critica de los aprendices de lenguas extranjeras em entornos digitales. Ocnos, n. 13, p. 7-23, 2015.

WHITE, David; CORNU, Alison Le. Visitors and Residents: A new typology for online engagement. Revista First Monday, vol. 16. N. 09. 2011.

Recebido em: 20/01/2020.

Aprovado em: 20/05/2020. 